\title{
Role of Neutrophils Apoptosis in Osteomyelitis Pathogenesis
}

Victor Asensi ${ }^{1 *}$, Julio Collazos ${ }^{2}$, Antonio Celada $^{3}$ and Eulalia Valle-Garay ${ }^{4}$

${ }^{1}$ Infectious Diseases Unit, Hospital Universitario Central de Asturias, University Medical School, Oviedo, Spain

${ }^{2}$ Infectious Diseases Unit, Hospital de Galdácano, Vizcaya, Spain

${ }^{3}$ Department of Immunology, University of Barcelona, Barcelona, Spain

${ }^{4}$ Biochemistry and Molecular Biology Department, Hospital Universitario Central de Asturias, University Medical School, Oviedo, Spain

"Corresponding author: Victor Asensi, Infectious Diseases Unit, Hospital Universitario Central de Asturias, Avenida de Roma, 33011 Oviedo, Spain, Tel: +34-985108000; E-mail: vasensia@gmail.com

Received date: January 23, 2017; Accepted date: January 25, 2017; Published date: January 30, 2017

Copyright: (c) 2017 Asensi V, et al. This is an open-access article distributed under the terms of the Creative Commons Attribution License, which permits unrestricted use, distribution, and reproduction in any medium, provided the original author and source are credited.

\section{Editorial}

Osteomyelitis is a bone infection characterized by progressive inflammatory destruction of the infected bone and new apposition of bone at the site of infection. In adults, osteomyelitis is usually a complication of open wounds due to fractures, surgery, or both, with or without the presence of foreign bodies such as prosthetic devices. In fact, it is estimated that about 0.4 to $7 \%$ of trauma and orthopaedic interventions are complicated by osteomyelitis [1-6].

Bone infections can also be the result of bacteraemia, mostly in children and in elderly patients, in whom the infection involves mainly the axial skeleton. The microorganism most frequently isolated in both post-traumatic and haematogenous cases is Staphylococcus aureus. Osteomyelitis constitutes a difficult-to-treat infection, with high rates of recurrence of about $20-30 \%$ despite appropriate medical and surgical therapies, causing significant morbidity and mortality [7-13].

Much attention has been dedicated to improving the medical and surgical treatments of osteomyelitis, but little progress has been made toward understanding its pathogenesis. It is clear that it is multifactorial and influenced mainly by local factors related to the bone lesion and microorganisms inoculated into the bone, but inherited factors and cell immunity dysfunctions could play some role as well [14-26].

\section{The neutrophils in the pathogenesis of osteomyelitis}

Neutrophils are key elements in the cellular defense against bacterial infections. Therefore, changes in their apoptotic regulation in patients with osteomyelitis might modify their phagocytic activity or lifespan, leading to suboptimal responses to infection.

Neutrophils play a dual activity in the focus of infection. On one hand they contribute to phagocytosis and elimination of bacteria. On the other hand phagocytosis of bacteria by activation of neutrophils elicits production of NADPH oxidase-derived superoxide, which is converted into other highly toxic reactive oxygen species (ROS) and reactive nitrogen species (RNS), which play a critical role in the bacteria-induced apoptosis and/or in the phagocytosis-induced cell death [27-29]. Neutrophils lysis also promotes host tissue destruction and inflammation. In addition to the neutrophils, there is also a mobilization of macrophages that work as true scavengers, removing apoptotic neutrophils and contributing to tissue repair (Figure 1).

In summary, the delay of neutrophils' apoptosis at the infection focus would contribute to the resolution of the infection, while its acceleration would favour the persistence of the infection. Therefore, it is critical to understand the mechanisms of apoptosis of the neutrophils and its regulation in osteomyelitis and other bacterial infections.

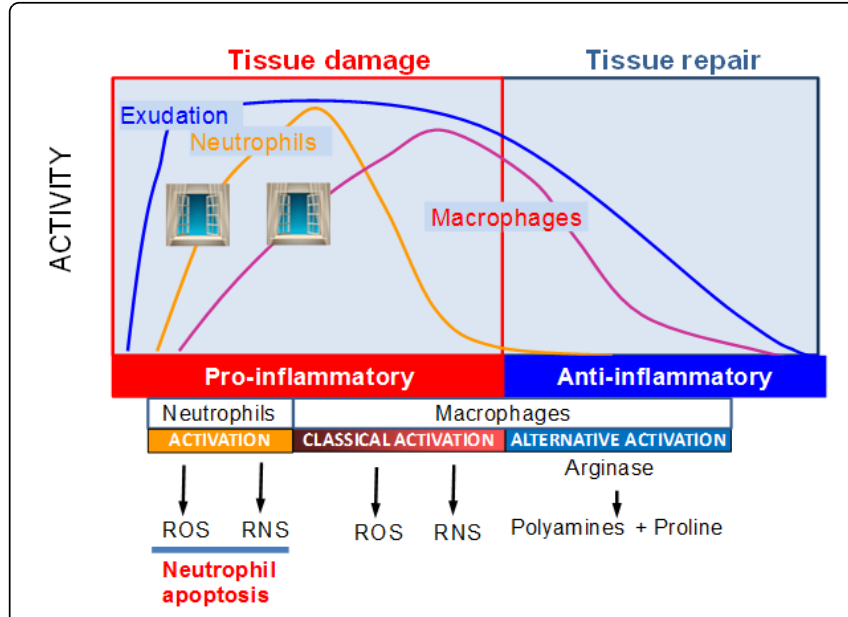

Figure 1: Diagram of the pro- and anti-inflammatory activity in the infectious process.

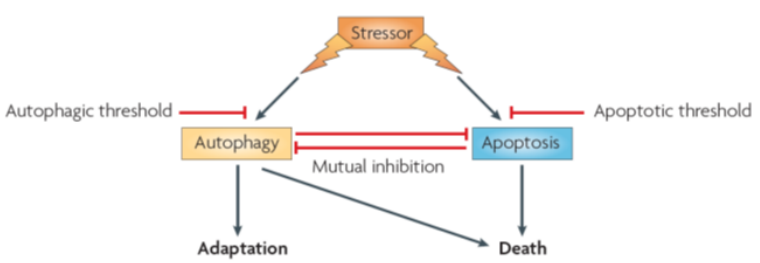

Figure 2: Mechanisms of defense against cellular stress (from Maiuri et al. [30]).

\section{Mechanisms of defense against a stress or cellular aggression}

Autophagy is a natural and self-destructive process in which the cell eliminates unnecessary or non-functional elements. The cell might respond against a stressor or nocive agent by activating autophagic and/or apoptotic mechanisms, leading to an adaptation to the stress or to cell death. The intensity of the stress with different sensitivity 
thresholds will determine if the cell develops autophagy or apoptosis. The choice between apoptosis or autophagy is also influenced by the fact that the two catabolic processes show some degree of mutual inhibition. A mixed phenotype of apoptosis and autophagy can be detected at the single-cell level. Although autophagy mostly allows the cell adaptation to stress, massive autophagy can also kill cells as apoptosis does (Figure 2) [30].

\section{Differences between apoptosis and necrosis}

There is a clear difference between apoptosis (programed cell death) and necrosis (accidental death). During necrosis there are changes in the cellular nucleus with chromatin clumping, and swelling of the organelles, including flocculent mitochondria. The overall process leads to disintegration of the cell and release of its intracellular contents producing inflammation. However, during apoptosis there is shrinkage of the cellular nucleus with chromatin compaction and segregation, and cytoplasm condensation. In a further step, nuclear fragmentation, blebbing and formation of apoptotic bodies occur. As opposed to necrosis, there is no inflammation in apoptosis (Figure 3).

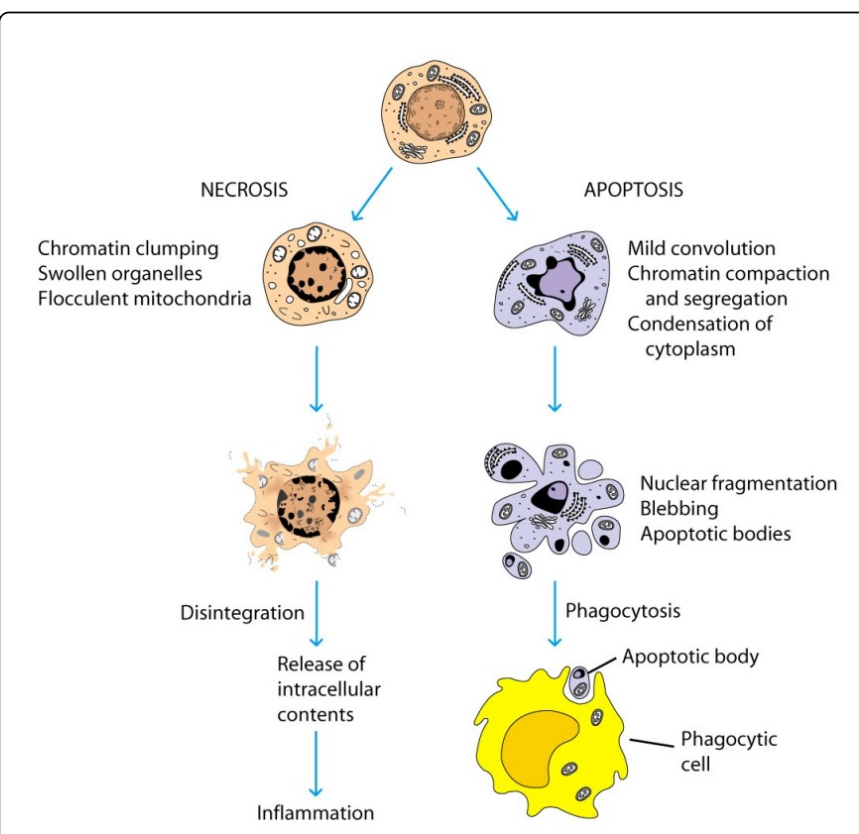

Figure 3: Differences between apoptosis (programmed cell death) and necrosis (accidental death).

\section{Cellular apoptosis induction and regulation pathways}

Cellular apoptosis has two triggering pathways (Figure 4). The extrinsic one is mediated by receptor-ligand interactions through Fas and TNF receptors. The other is an intrinsic pathway, in which sensors of the Bcl-2 family detect some deficiency of growth factors, survival signals, DNA damage or protein misfolding.

Once these receptors are activated, apoptosis starts at the mitochondrial level, where different stimuli block anti-apoptotic proteins (Bcl-2, Bcl-xl) and activate pro-apoptotic proteins (Bax, Bak) [31-34]. Pro-apoptotic proteins initiate the caspases pathway leading to DNA and nuclear fragmentation, breakdown of the cytoskeleton and formation of apoptotic bodies that are phagocyted by macrophages.
Other changes observed in apoptosis include modifications in the cell membrane with phosphatidylserine externalization, $\mathrm{pH}$ acidification and increase of $\mathrm{Ca}^{2+}$ concentration at the intracellular level.

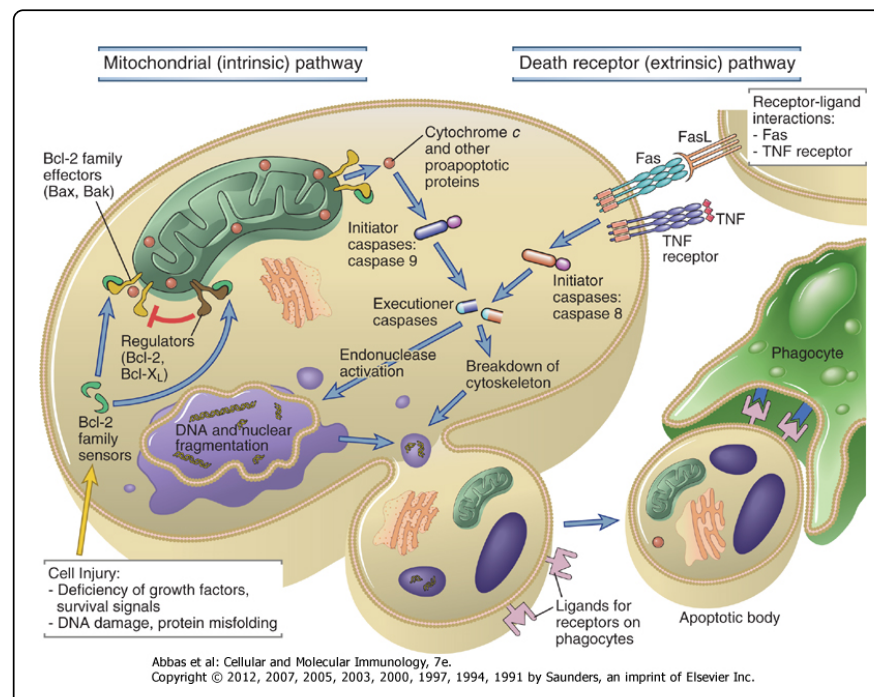

Figure 4: Cellular apoptosis induction pathways (from Abbas et al. [31]).

It has recently been reported that stimulated neutrophils generate a burst of ROS that induce DNA damage signaling in activated neutrophils and macrophages, suppressing cytokine production and inducing apoptosis. If the DNA damage reparative systems are effective cells will survive, otherwise they will become apoptotic and die [35-37].

\section{Delay of neutrophils apoptosis in osteomyelitis}

Neutrophils of peripheral blood of patients with osteomyelitis showed a delayed apoptosis compared to neutrophils from healthy donors, an anti-apoptotic effect that seems to be serum-mediated [38]. Patients with osteomyelitis have increased serum levels of C-reactive protein and several cytokines, especially IL-6, a cytokine usually associated with infection [38]. An inverse correlation between serum levels of IL- 6 and neutrophils apoptosis has been observed, and the anti-apoptotic effect of osteomyelitis serum reverted after its incubation with an anti-IL-6 monoclonal antibody [38]. These observations support that the anti-apoptotic effect of osteomyelitis serum is related to IL-6.

\section{Delay of neutrophils apoptosis after bacterial phagocytosis}

Bacterial phagocytosis influences the "in vitro" apoptosis of neutrophils, an effect that seems to be dependent of the bacteria/ neutrophil ratio. Thus, for a bacteria/neutrophil ratio of $1 / 1$, phagocytosis of $S$. aureus and E. coli delayed neutrophils apoptosis as compared to controls, whereas for higher bacteria/neutrophil ratios (10/1 to 100/1) bacterial phagocytosis increased neutrophils apoptosis. The anti-apoptotic effect was observed as well after incubation of neutrophils with LPS or lipoteichoic acid, components of the cellular wall of Gram negative and Gram positive bacteria, respectively [39].

Also, phagocytosis of $S$. aureus, and E. coli and incubation with LPS and lipoteichoic acid increased the "in vitro" production of IL-6, IL- $1 \beta$ and TNF- $\alpha$ by the neutrophils, and the incubation with anti-IL- 6 and 
Page 3 of 4

anti-TNF- $\alpha$ monoclonal antibodies reduced the anti-apoptotic effect of bacterial phagocytosis at low bacteria/neutrophil ratios [36].

Regarding the pro- and anti-apoptotic proteins regulation, bacterial phagocytosis at low bacteria/neutrophil ratios delayed the apoptosis of the neutrophils by decreasing the expression of Bax- $\alpha$ pro-apoptotic protein and the Bax- $\alpha / \mathrm{Bcl}-\mathrm{Xl}$ proteins ratio, and the incubation with recombinant de IL- 6 delayed the apoptosis of the neutrophils by decreasing the Bax- $\alpha / \mathrm{Bcl}-\mathrm{Xl}$ proteins ratio [39].

\section{Genetic aspects and apoptosis of the neutrophils}

Different reports have shown that the $G(-248) A$ polymorphism of the promoter of the $B A X$ gene delayed cellular apoptosis of leukemic cells $[40,41]$, and this polymorphism could also influence the lifespan of peripheral blood neutrophils of patients with osteomyelitis [42].

In fact, carriers of the $A$ allele of the $G(-248) A$ polymorphism of the promoter region of the $B A X$ gene were more frequent among osteomyelitis patients compared to healthy donors, and the apoptosis of neutrophils of carriers of this variant $A$ allele was delayed compared to carriers of the wild type $G G$ genotype of this polymorphism [42].

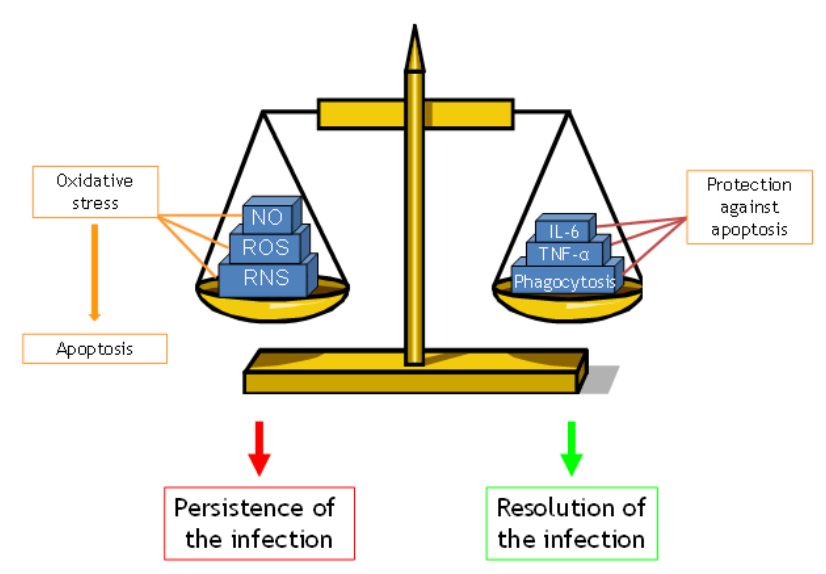

Figure 5: Simplified diagram of the factors influencing neutrophils survival during the infection.

\section{Effect of neutrophils apoptosis on the outcome of the infection}

There are factors associated with stress such as nitric oxide (NO) and the formation of ROS and RNS that accelerate the apoptosis of the neutrophils and contribute to perpetuate the infection. On the other hand, bacterial phagocytosis at low bacteria/neutrophil ratios (1/1) and cytokines IL- 6 and TNF- $\alpha$ delay the apoptosis of the neutrophils and would contribute to resolve the infection (Figure 5).

\section{Conclusions}

Neutrophils are the first line of the host immune defense against microorganisms, especially bacteria. Osteomyelitis patients have a delayed apoptosis of peripheral blood neutrophils. This apoptotic delay seems to be due to the autocrine production of IL- 6 , induced by bacterial phagocytosis, which decreases the Bax- $\alpha / \mathrm{Bcl}-\mathrm{Xl}$ proteins expression ratio. This increased lifespan would allow the neutrophils to remain longer in the septic focus and might help to resolve the bacterial infection. Genetic aspects, such as the carriage of the $G(-248) A$ polymorphism of the promoter of the $B A X$ gene, seems also to delay neutrophils apoptosis and, consequently, could favour the resolution of the infection. Additional studies are necessary to evaluate the role of apoptosis in osteomyelitis and to clarify if patients with delayed neutrophils apoptosis have better osteomyelitis outcomes in terms of cure and sequelae than those with normal or reduced neutrophils lifespan.

\section{References}

1. Calhoun JH, Manring MM, Shirtliff M (2009) Osteomyelitis of the long bones. Semin Plast Surg 23: 59-72.

2. Lew DP, Waldvogel FA (1997) Osteomyelitis. N Engl J Med 336: 999-1007.

3. Roesgen M, Hierholzer G, Hax PM (1989) Post-traumatic osteomyelitis. Pathophysiology and management. Arch Orthop Trauma Surg 108: 1-9.

4. Cierny G, Mader JT (1984) Adult chronic osteomyelitis. Orthopedics 7: 1557-1564.

5. Arias CA, Betancur MCT, Pinzón MA, Arango DC, Taffur CAC, et al. (2015) Differences in the clinical outcome of osteomyelitis by treating specialty: Orthopedics or Infectology. PLoS One 10: e0144736.

6. Lew DP, Waldvogel FA (2004) Osteomyelitis. Lancet 364: 369-379.

7. Kindsfater K, Jonassen EA (1995) Osteomyelitis in grade II and III open tibia fractures with late debridement. J Orthop Trauma 9: 121-127.

8. Chihara S, Segreti J (2010) Osteomyelitis. Dis Month 56: 5-31.

9. Lin Z, Vasudevan A, Tambyah PA (2016) Use of erythrocyte sedimentation rate and C-reactive protein to predict osteomyelitis recurrence. J Orthop Surg 24: 77-83.

10. Tice AD, Hoaglund PA, Shoultz DA (2003) Outcomes of osteomyelitis among patients treated with outpatient parenteral antimicrobial therapy. Am J Med 114: 723-728.

11. Lipsky BA, Berendt AR, Deery HG, Embil JM, Joseph WS, et al. (2006) Diagnosis and treatment of diabetic foot infections. Clin Infect Dis 39: 885-910.

12. Tice AD, Hoaglund PA, Shoultz DA (2003) Risk factors and treatment outcomes in osteomyelitis. J Antimicrob Chemother 51: 1261-1268.

13. Roine I, Arguedas A, Faingezicht I, Rodriguez F (1997) Early detection of sequelae-prone osteomyelitis in children with use of simple clinical and laboratory criteria. Clin Infect Dis 24: 849-853.

14. Asensi V, Alvarez V, Valle E, Meana A, Fierer J, et al. (2003) IL-1 alpha $(-889)$ promoter polymorphism is a risk factor for osteomyelitis. Am J Med Gen 119A: 132-136.

15. Montes AH, Asensi V, Alvarez V, Valle E, Ocaña MG, et al. (2006) The Tolllike receptor 4 (Asp299Gly) polymorphism is a risk factor for Gramnegative and haematogenous osteomyelitis. Clin Exp Immunol 143: 404-413.

16. Asensi V, Montes AH, Valle E, Ocaña G, Astudillo A, et al. (2007) The NOS3 (27-bp repeat, intron 4) polymorphism is associated with susceptibility to osteomyelitis. Nitric Oxide 16: 44-53.

17. Tsezou A, Poultsides L, Kostopoulou F, Zintzaras E, Satra M, et al. (2008) Influence of interleukin 1 alpha (IL-1alpha), IL-4, and IL-6 polymorphisms on genetic susceptibility to chronic osteomyelitis. Clin Vaccine Immunol 15: $1888-1890$.

18. Montes AH, Valle-Garay E, Alvarez V, Pevida M, García Pérez E, et al. (2010) A functional polymorphism in MMP1 could influence osteomyelitis development. J Bone Miner Res 25: 912-919.

19. Valle-Garay E, Montes AH, Corte JR, Meana A, Fierer J, et al. (2013) tPA Alu (I/D) polymorphism associates with bacterial osteomyelitis. J Infect Dis 208: 218-223.

20. Osman AE, Mubasher M, ElSheikh NE, AlHarthi H, AlAlallah IA, et al. (2015) Investigation of polymorphisms in anti-inflammatory cytokine genes in hematogenous osteomyelitis. Genet Mol Res 14: 16981-16986.

21. Osman AE, Mubasher M, ElSheikh NE, AlHarthi H, AlZahrani MS, et al. (2016) Association of single nucleotide polymorphisms in pro- 
Citation: Asensi V, Collazos J, Celada A, Valle-Garay E (2017) Role of Neutrophils Apoptosis in Osteomyelitis Pathogenesis. Clin Microbiol 6: e139. doi:10.4172/2327-5073.1000e139

Page 4 of 4

inflammatory cytokine and toll-like receptor genes with pediatric hematogenous osteomyelitis. Genet Mol Res 15.

22. Jiang N, Zhao XQ, Qin CH, Hu YJ, Wang L, et al. (2016) Association of vitamin $\mathrm{D}$ receptor gene TaqI, BsmI, FokI and ApaI polymorphisms and susceptibility to extremity chronic osteomyelitis in Chinese population. Injury 47: 1655-1660.

23. Klosterhalfen B, Peters KM, Töns C, Hauptmann S, Klein CL, et al. (1996) Local and systemic inflammatory mediator release in patients with acute and chronic posttraumatic osteomyelitis. J Trauma 40: 372-378.

24. Yoon KS, Fitzgerald RH Jr, Sud S, Song Z, Wooley PH (1999) Experimental acute hematogenous osteomyelitis in mice. II. Influence of Staphylococcus aureus infection on T-cell immunity. J Orthop Res 17: 382-391.

25. Lee LY, Miyamoto YJ, McIntyre BW, Höök M, McCrea KW, et al. (2002) The Staphylococcus aureus Map protein is an immunomodulator that interferes with $\mathrm{T}$ cell-mediated responses. J Clin Invest 110: 1461-1471.

26. Kumar G, Roger PM, Ticchioni M, Trojani C, Bernard de Dompsur R, et al. (2014) T cells from chronic bone infection show reduced proliferation and a high proportion of CD28 CD4 T cells. Clin Exp Immunol 176: 49-57.

27. Watson RW, Redmond HP, Wang JH, Condron C, Bouchier-Hayes D (1996) Neutrophils undergo apoptosis following ingestion of Escherichia coli. J Immunol 156: 3986-3992.

28. Kobayashi SD, Braughton KR, Whitney AR, Voyich JM, Schwan TG, et al. (2003) Bacterial pathogens modulate an apoptosis differentiation program in human neutrophils. Proc Natl Acad Sci USA 100: 10948-10953.

29. DeLeo FR (2004) Modulation of phagocyte apoptosis by bacterial pathogens. Apoptosis 9: 399-413.

30. Maiuri MC, Zalckvar E, Kimchi A, Kroemer G (2007) Self-eating and selfkilling: crosstalk between autophagy and apoptosis. Nat Rev Mol Cel Biol 8: 741-752.

31. Abbas Abbas AK, Lichtman AHH, Pillai S (2012) Cellular and Molecular Immunology. 7th ed. Saunders, Elsevier ed.

32. Akgul C, Edwards SW (2003) Regulation of neutrophil apoptosis via death receptors. Cell Mol Life Sci 60: 2402-2408.
33. Borner C (2003) The Bcl-2 protein family: sensors and checkpoints for lifeor-death decisions. Mol Immunol 39: 615-647.

34. Simon HU (2003) Neutrophil apoptosis pathways and their modifications in inflammation. Immunol Rev 193: 101-110.

35. Harbort CJ, Soeiro-Pereira PV, von Bernuth H, Kaindl AM, CostaCarvalho BT, et al. (2015) Neutrophil oxidative burst activates ATM to regulate cytokine production and apoptosis. Blood 126: 2842-2851.

36. Pereira-Lopes S, Tur J, Calatayud-Subias JA, Lloberas J, Stracker TH, et al. (2015) NBS1 is required for macrophage homeostasis and functional activity in mice. Blood 126: 2502-2510.

37. Tur J, Vico T, Lloveras J, Zorzano A, Celada A (2017) Macrophages and mitochondria: a critical interplay between metabolism, signaling, and the functional activity. Adv Immunol (in press).

38. Asensi V, Valle E, Meana A, Fierer J, Celada A, et al. (2004) In vivo interleukin-6 protects neutrophils from apoptosis in osteomyelitis. Infect Immun 72: 3823-3828.

39. Ocaña MG, Asensi V, Montes AH, Meana A, Celada A, et al. (2008) Autoregulation mechanism of human neutrophil apoptosis during bacterial infection. Mol Immunol 45: 2087-2096.

40. Saxena A, Moshynska O, Sankaran K, Viswanathan S, Sheridan DP (2002) Association of a novel single nucleotide polymorphism, G(-248)A, in the 5'-UTR of BAX gene in chronic lymphocytic leukemia with disease progression and treatment resistance. Cancer Lett 187: 199-205.

41. Moshynska O, Sankaran K, Saxena A (2003) Molecular detection of the G (-248)A BAX promoter nucleotide change in B cell chronic lymphocytic leukaemia. Mol Pathol 56: 205-209.

42. Ocaña M, Valle-Garay E, Montes AH, Meana A, Cartón JA, et al. (2007) Bax gene G(-248)A promoter polymorphism is associated with increased lifespan of the neutrophils of patients with osteomyelitis. Genet Med 9: 249-255. 